\title{
A novel highly frequent single-nucleotide polymorphism site of cadherin 23 in clear cell renal cell carcinoma with sarcomatoid differentiation based on whole exome sequencing
}

\author{
WENJUAN YU ${ }^{1}$, XIAOHUI WANG ${ }^{1}$, YUEWEI WANG ${ }^{2}$, YANXIA JIANG ${ }^{1}$, WEI ZHANG ${ }^{3}$, \\ HAILEI SHI ${ }^{1}$ and YUJUN LI ${ }^{1}$ \\ ${ }^{1}$ Department of Pathology, The Affiliated Hospital of Qingdao University, Qingdao, Shandong 266003; \\ ${ }^{2}$ Department of Vascular Surgery, The Affiliated Hospital of Qingdao University, Qingdao, Shandong 266003; \\ ${ }^{3}$ Department of Pathology, 971 Navy Hospital of Chinese People's Liberation Army, Qingdao, Shandong 266071, P.R. China
}

Received November 13, 2019; Accepted March 20, 2020

DOI: 10.3892/or.2020.7613

\begin{abstract}
Clear cell renal cell carcinoma (CCRCC) with sarcomatoid differentiation (CCRCCS) displays invasive behavior, poor prognosis, and poor therapeutic response. The present study was aimed to gain new insights into the molecular mechanisms of sarcomatoid transformation, and identify new prognostic and therapeutic targets for CCRCCS. Whole exome sequencing was performed on matched carcinomatous and sarcomatoid elements from five specimens with CCRCCS. A non-synonymous single-nucleotide polymorphism (SNP) of cadherin 23 (CDH23) was further studied through Sanger sequencing in expanded 40 specimens with CCRCCS and 50 specimens with CCRCC. Carcinomatous and sarcomatoid elements shared most somatic single-nucleotide variants (SSNVs) as revealed through whole exome sequencing. Sarcomatoid element had higher overall SSNVs than carcinomatous element. A highly frequent mutation of CDH23 (rs3802711) was observed in CCRCCS that resulted in an alteration in the highly conserved calcium-binding site in the three-dimensional (3D) structure mediating the functions of cadherins. In the expanded 90 specimens, CDH23 SNP (rs3802711) was a highly frequent mutation in CCRCCS than that in all CCRCC samples and even high grade CCRCC. Cox multivariate analysis indicated that CDH23 (rs3802711) genotype was an independent prognostic factor affecting the overall survival of the cohort. $\mathrm{CDH} 23$ gene and protein were negatively or weakly expressed in most CCRCCS specimens with CDH23 mutation. The present study revealed, for the
\end{abstract}

Correspondence to: Dr Wenjuan Yu or Dr Yujun Li, Department of Pathology, The Affiliated Hospital of Qingdao University, 16 Jiangsu Road, Qingdao, Shandong 266003, P.R. China

E-mail: wenjuan801023@163.com

E-mail: yujunli66@126.com

Key words: $\mathrm{CDH} 23$, exome sequencing, carcinomatous, sarcomatoid, clear cell renal cell carcinoma first time, that the $\mathrm{CDH} 23$ (rs3802711) was a highly genetic risk factor for CCRCCS. It was associated with the decreased expression of $\mathrm{CDH} 23$ protein, resulting in the absence of cadherin function of $\mathrm{CDH} 23$, indicating that the $\mathrm{CDH} 23$ mutation may be involved in the sarcomatoid transformation in CCRCCS. Collectively, a novel and specific SNP of CDH23 was identified in CCRCCS and a new candidate cadherin involved in EMT was revealed. Furthermore, a new prognostic evaluation factor and potential therapeutic target for CCRCCS was identified.

\section{Introduction}

Renal cell carcinoma (RCC) with sarcomatoid differentiation is a relatively rare renal tumor, and clear cell renal cell carcinoma (CCRCC) with sarcomatoid differentiation accounts for approximately $79 \%$ (1). According to the World Health Organization (WHO) 2016 classification system, RCC with sarcomatoid differentiation was not classified into a distinct subtype, however, it is considered to be a specific histological characteristic of RCC $(2,3)$. CCRCC with sarcomatoid differentiation (CCRCCS) is of Fuhrman IV grade, however, its prognosis is worse in comparison to other high-grade RCCs. Approximately $80 \%$ of patients have been reported to be prone to distant metastasis with a median overall survival of only 5.8 months, and $38 \%$ of patients had a survival of one year. The mortality rate of CCRCCS has been reported to be 3.2 times higher than that of CCRCC due to its poor response to systemic therapy and owing to lack of any ideal therapeutic strategy (4-6).

Although great progress has been made in understanding RCC, molecular mechanisms of sarcomatoid differentiation have not yet been fully elucidated (7) According to a current prevailing theory, sarcomatoid elements represent a subclonal dedifferentiation or transformation from carcinomatous elements based on their shared genetic patterns, such as X chromosome inactivation and sarcomatoid element specific mutation, including high frequent TP53, ARID1A, and BAP1 mutations $(6,8,9)$. Furthermore, frequently reduced expression of epithelial adhesion molecules, such as E-cadherin and aberrant expression of 
$\mathrm{N}$-cadherin suggested that epithelial-mesenchymal transformation (EMT) may be involved in the development of sarcomatoid elements $(9,10)$.

To further expound the underlying molecular basis of sarcomatoid differentiation in CCRCC, whole exome sequencing of matched carcinomatous-sarcomatoid specimens of the same tumor from five patients with CCRCCS was performed. Numerous candidate genes were screened from the results of whole exome sequencing, and of the identified genes, a cadherin gene, $\mathrm{CDH} 23$, that displayed a highly frequent mutation, drew our attention. A single-nucleotide polymorphism (SNP) site of $\mathrm{CDH} 23$ (rs3802711) was identified concurrently in the exon areas of three groups of sarcomatoid elements and two groups of carcinomatous elements. $\mathrm{CDH} 23$ is an atypical cadherin that lacks the $\beta$-catenin binding motif, and anchors to the actin cytoskeleton to mediate inter- and intracellular adhesion (11). Studies on CDH23 have confirmed its association with autosomal recessive non-syndromic hearing loss (ARNSHL), sensorineural deafness (DFNB12) and Usher syndrome type 1D (USH1D), age-related HL, and noise induced HL $(12,13)$.

However, the role $\mathrm{CDH} 23$ in cancer has not been elucidated yet. It has been reported that cadherins play key roles in the EMT of tumors which is a key factor in the progression and metastasis of malignant tumors (14). Therefore, our study was further expanded to another 40 specimens with CCRCCS and 50 specimens with CCRCC by conducting Sanger sequencing to identify the SNP status of CDH23. Concomitantly, the gene and protein expressions of $\mathrm{CDH} 23$ were detected, and the association between its mutation and a series of clinicopathological features was also investigated. Therefore, the aim of the present study, was to provide new insights into the molecular mechanisms of sarcomatoid transformation of CCRCC and identify novel gene targets for prognostic predication and therapy of CCRCCS.

\section{Materials and methods}

Sample collection for whole exome sequencing. Whole exome sequencing of five matched carcinomatous-sarcomatoid paraffin-embedded specimens with CCRCCS, was performed. The age range of the 5 patients was 53-70 years old (with a median age of 62 years), including 3 males and 2 females. Tissues were fixed with $4 \%$ neutral formaldehyde and embedded in paraffin, and all sections were $4-\mu \mathrm{m}$-thick for H\&E staining. After deparaffinization and hydration, sections were stained with hematoxylin for $5 \mathrm{~min}$ and stained with eosin for $3 \mathrm{~min}$. After dehydration and transparency, the sections were sealed with neutral gum. Carcinomatous and sarcomatoid areas were labeled under a light microscope (x4; OLYMPUS BX41 Olympus Corporation) after H\&E staining and separately dissected into $10-\mu \mathrm{m}$ thick sections for DNA extraction and whole exome sequencing. All sections were confirmed by two experienced pathologists. All patients provided informed consent and the study was approved by the Ethics Committee of The Affiliated Hospital of Qingdao University, and was conducted in full compliance with all the principles of the Helsinki Declaration.

DNA extraction, exome capture, and whole exome sequencing. DNA was extracted from formalin-fixed, paraffin-embedded
(FFPE) blocks of five matched carcinoma-sarcomatoid tissues using GenElute FFPE DNA Purification Kit (Sigma-Aldrich; Merck KGaA). Exome capture was performed using Roche NimbleGen SeqCap EZ Exome V3 based on the manufacturer's instructions. Thereafter, paired-end sequencing was performed using Illumina HiSeq 4000 (Illumina, Inc.). Sequences were aligned to the human reference genome (UCSC hg19) using Burrows-Wheeler Aligner (BWA) software $(15,16)$ SSNV calling was performed using Mutect (http://www.broadinstitute.org/cancer/cga/mutect) (17). Single-nucleotide variant (SNV) and SNP were detected using Genome Analysis Tool Kit (GATK 4.1.0.0) (https://gatk.broadinstitute.org/hc/en-us) (18) and annotated through ANNOVAR (20180416) $(19,20)$. Kyoto Encyclopedia of Genes and Genomes (KEGG) (https://www. genome.jp/kegg/) annotation and Gene Ontology (GO) (http:// geneontology.org/) annotation were applied to annotate the function of the variant genes.

Candidate gene selection. Among numerous mutant genes, we focused on the common mutant genes that occurred in more than three groups of carcinomatous elements or three groups of sarcomatoid elements to identify the most possible pathogenic genes of CCRCCS. A non-synonymous SNP site in the exon 40 of CDH23 (rs3802711), a cadherin gene, that may be related to EMT in tumors, was selected for further study. Evolutionary conserved sequences and structures of the protein and nucleic acid of CDH23 were assessed through the National Center for Biology Information (NCBI). The effect of the identified novel non-synonymous mutation was assessed using PolyPhen-2 tool (http://genetics.bwh.harvard.edu/pph2/) (21) for prediction of the possible impact of an amino acid substitution on the structure and function of a human protein. The 3D molecular structure of the extracellular domain (EC) of $\mathrm{CDH} 23$ was modeled using SWISS-MODEL (https://swissmodel.expasy. org/interactive) (22).

Expanded specimen acquisition and Sanger sequencing for CDH23. A total of 40 specimens with CCRCCS (the median age: 63 years old, including 30 males and 10 females) and 50 specimens with CCRCC (the median age: 59 years old, including 32 males and 18 females) were collected from The Affiliated Hospital of Qingdao University from January 2008 to October 2018, and reviewed by two genitourinary pathologists. The clinicopathological characteristics and survival data of the patients were collected. Matched carcinomatous, sarcomatoid tissues and normal renal tissues were labeled under a light microscope after H\&E staining as aforementioned, and separately dissected into $10-\mu \mathrm{m}$ thick sections. Thereafter, DNA extraction and Sanger sequencing were performed to assess the genotype of the CDH23 gene at a base position of 5411 from FFPE samples. In accordance with the results of whole-exome sequencing, the specific PCR primers were designed and custom synthesized (Shenggong Techonology). The PCR primers were designed as follows: Forward, 5'-GGG CAC AGA TGG TCA GGGT TG-3' and reverse, 3'-ACC TGT GAC GAG TGA GGC TT-5'. The amplified PCR products were used for Sanger sequencing (Shenggong Techonology). Subsequently, the sequencing results were screened using Chromas program (2.6.5) (Technelysium Pty Ltd.) and analyzed manually. 
Quantitative real-time PCR $(R T-q P C R)$ to detect the expression of the $\mathrm{CDH} 23$ gene. $\mathrm{CDH} 23$ gene expression was successfully detected in 21 cases with CCRCCS and 34 cases with CCRCC through RT-qPCR using SuperScript ${ }^{\mathrm{TM}}$ IV First-Strand Synthesis System (cat. no. 18091050, Thermo Fisher, Scientific, Inc.) and Power SYBR ${ }^{\circledR}$ Green Master Mix (cat. no. 4367659, Thermo Fisher, Scientific, Inc.) after the total RNA extraction from paraffin-embedded tissues using the Total RNA Extraction Kit (cat. no. DP439; Tiangen Biotech Co., Ltd.). The PCR primers for $\mathrm{CDH} 23$ gene were designed as follows: Forward, 5'-CCGGCTGCCCTTCTTCACCAACCA-3' and reverse, 5'-GGCCTCCTCCCCAGACA CGCC-3'. The GAPDH gene was used as the control. The PCR primers for the GAPDH gene were: Forward, 5'-GGATTTGGTCGTATTGGG-3' and reverse, 5'-GGAAGATGGTGATGGGATT-3'. The thermal cycling protocol was: $95^{\circ} \mathrm{C}$ for $5 \mathrm{~min}, 1$ cycle; $95^{\circ} \mathrm{C}$ for $1 \mathrm{~min}, 60^{\circ} \mathrm{C}$ for $30 \mathrm{sec}$ and $72^{\circ} \mathrm{C}$ for $30 \mathrm{sec}, 38$ cycles; $72^{\circ} \mathrm{C}$, $10 \mathrm{~min}, 1$ cycle. PCR was performed on Applied Biosystems 7500 Real-Time PCR System (Thermo Fisher, Scientific, Inc.). Relative expression was calculated using the $2^{-\Delta \Delta \mathrm{Cq}}$ method (23).

Immunohistochemistry. Immunohistochemistry was performed on $4-\mu \mathrm{m}$ thick sections of 90 FFPE samples. The primary antibody used in the present study was $\mathrm{CDH} 23$ rabbit polyclonal antibody (cat. no. PA5-53564, Thermo Fisher, Scientific, Inc.). All immunohistochemistry sections were analyzed using Roche BenchMark XT fully automatic IHC/ ISH instrument following the optimized protocols. The known positive sections were used as a positive control, and phosphate-buffered saline (PBS) was used as a negative control instead of a primary antibody.

The results were determined using a double-blind method. Concurrently, each section was observed independently by two senior pathologists. CDH23 was positively expressed at the cytomembrane and/or cytoplasm. The positive staining was initially scored as $0,1,2$, and 3 based on the staining intensity (no staining, faint, mild, and strong, respectively) and the percentage of positively-stained cells $(0 \%, \leq 25 \%, \sim 26-75 \%$, and $>75 \%$ ), respectively. Subsequently, the two scores were multiplied, and a positive score indicated that the product of the two fractions was $>4$.

Clinical follow-up and survival analysis. Follow-up data were collected for 34 cases with CCRCCS and 41 cases with CCRCC. Survival was calculated from the date of surgery to the death or the last follow-up visit. For the analysis, only deaths for RCCs were considered as events. Survival curves were derived from Kaplan-Meier analysis and log-rank test to compare overall survival between CCRCCS and CCRCC based on different clinicopathological features. Furthermore, to investigate the factors that may affect survival patterns, the P-values for prognostic factors analysis were adjusted for multiple analysis using Cox regression model.

Statistical analysis. SPSS 20.0 software (IBM Corp.) was used for statistical analysis. The differences in clinicopathological characteristics, $\mathrm{CDH} 23$ genotypes, $\mathrm{CDH} 23$ gene and protein expression between CCRCCS and CCRCC were evaluated by Chi-square test, Fisher's exact test or T-test. The associations between $\mathrm{CDH} 23$ genotype and clinicopathological characteristics were evaluated by Chi-square test or Fisher's exact test. Furthermore, the correlation between $\mathrm{CDH} 23$ genotype and protein expression was analyzed by Pearson correlation test. Two-tailed tests were used for all comparisons, and $\mathrm{P}<0.05$ was considered to indicate a statistically significant difference.

\section{Results}

Whole exome sequencing. The median of the cleaned bases of ten samples was observed to be $10.74 \mathrm{Gbp}$. The average contrast efficiency between the samples and the reference genome UCSC hg19 was observed to be $99.74 \%$. The median sequencing depth of the target area was 76.89X.

Somatic single nucleotide variants (SSNVs) in CCRCCS were first screened in the five groups through whole exome sequencing. The number of common SSNVs in more than one group, each belonging to carcinomatous and sarcomatoid elements, were observed to be 1544 and 1653, respectively. Carcinomatous and sarcomatoid elements were found to share most SSNVs (1198). Sarcomatoid elements had a higher overall SSNV burden than carcinomatous elements (1653 vs. 1544) (Fig. 1A).

While investigating the element-specific mutant genes, a total of 679 candidate genes, including 319 common mutant genes occurring in more than three groups of carcinomatous elements, and 360 common mutant genes emerging in more than three groups of sarcomatoid elements, were obtained. The 679 candidate genes comprised 12 genes in the downstream area, 61 genes in the exonic region, 167 genes in the intergenic region, 316 genes in the intronic region, 18 genes in ncRNA_exonic region, 45 genes in the ncRNA_intronic region, 12 genes in the upstream area, 37 genes in the UTR3, and 11 genes in the UTR5 (Fig. 1B). The results of KEGG pathway enrichment revealed that most mutant genes in carcinomatous elements were involved in the same functions as those in sarcomatoid elements, such as gap junction, endocytosis, phagosome, calcium signaling pathway, Rap1 signaling pathway, and neuroactive ligand-receptor interaction (Fig. 2A and B). However, some mutant genes played specific roles in carcinomatous elements, including Ras signaling pathway, cell adhesion molecules, cytokine-cytokine receptor interaction, and central carbon metabolism in cancer (Fig. 2A). Furthermore, in sarcomatoid element, some distinct genes were involved in specific functions, such as, regulation of actin cytoskeleton, local adhesion, FOXO signaling pathway, MAPK signaling pathway, PI3K/Akt signaling pathway, and vascular smooth muscle contraction (Fig. 2B). Moreover, GO enrichment analysis revealed the mutant genes in carcinomatous elements (Fig. S1) and sarcinomatoid elements (Fig. S2), including the genes involved in biological processes, cellular components and molecular functions.

Among them, there were 25 common mutant genes in more than three groups of carcinomatous elements in the exon region, including 12 synonymous mutant genes and 13 non-synonymous mutant genes. The 13 non-synonymous mutant genes were KIF17, MROH2B, UBQLN3, HLA-DPB1, RP1L1, SBSPON, IQCE, FMN1, ZNF592, ALPK2, FGCBP, C19orf54, and ZFHX3 (Table I). A total of 21 common mutant 
A

\begin{tabular}{|c|c|c|c|c|}
\hline & & $\begin{array}{l}\text { Carcinomatous } \\
\text { element }\end{array}$ & $\begin{array}{l}\text { Sarcomatoid } \\
\text { element }\end{array}$ & Shared \\
\hline \multicolumn{2}{|c|}{ Element-specific } & 346 & 455 & 1198 \\
\hline \multicolumn{2}{|l|}{ Total } & 1544 & 1653 & 1198 \\
\hline \multicolumn{5}{|c|}{ Carcinomatous specific $\square$ Sarcomatoid specific $\square$ Shared } \\
\hline \multicolumn{5}{|l|}{1800} \\
\hline \multicolumn{5}{|l|}{1600} \\
\hline \multicolumn{5}{|l|}{1400} \\
\hline \multicolumn{5}{|l|}{1200} \\
\hline \multicolumn{5}{|l|}{1000} \\
\hline \multicolumn{5}{|l|}{800} \\
\hline \multicolumn{5}{|l|}{600} \\
\hline \multicolumn{5}{|c|}{400} \\
\hline \multicolumn{5}{|l|}{200} \\
\hline \multicolumn{3}{|c|}{ Carcinomatous element } & Sarcomatoid $\mathrm{e}$ & nent \\
\hline
\end{tabular}

B

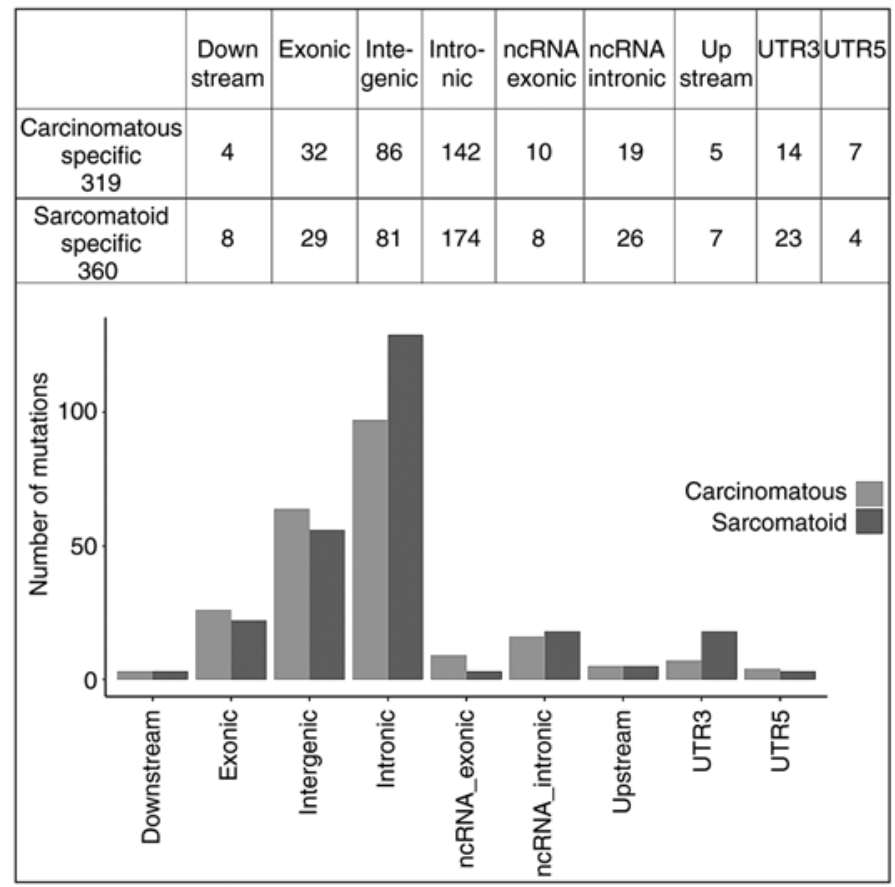

Figure 1. The results of whole exome sequencing. (A) SSNVs of paired carcinomatous-sarcomatoid elements of five specimens with CCRCCS. (B) The element-specific mutant genes in more than three groups of carcinomatous elements or sarcomatoid elements. SSNVs, somatic single nucleotide variants; CCRCCS, clear cell renal cell carcinoma with sarcomatoid differentiation.
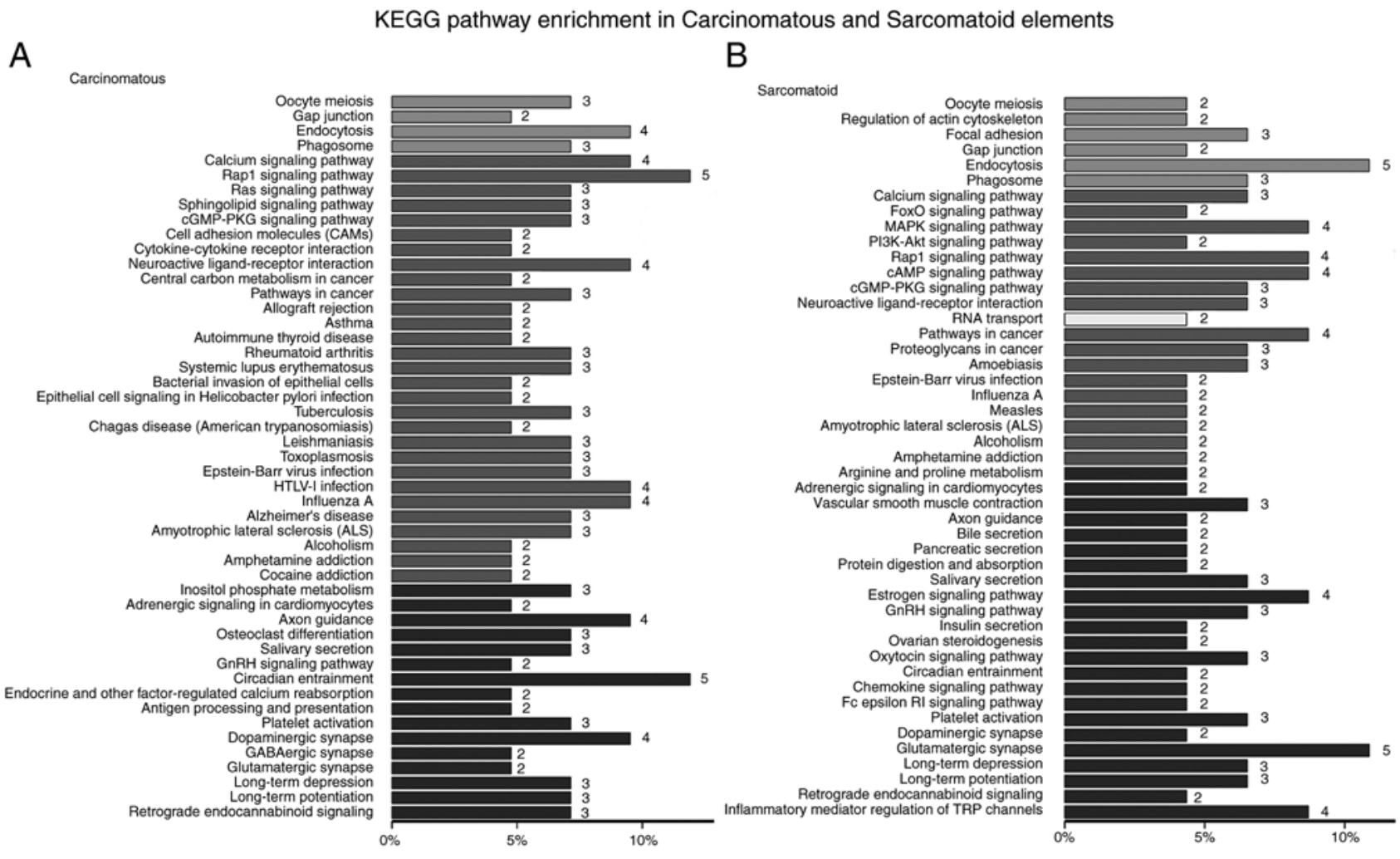

Figure 2. The results of KEGG pathway enrichment revealed most mutant genes in carcinomatous elements were involved in the same functions as those in sarcomatoid elements. Some mutant genes played specific roles in (A) carcinomatous elements and (B) sarcomatoid elements.

genes were identified in more than three groups of sarcomatoid elements in the exon region, including 13 synonymous mutant genes and 8 non-synonymous mutant genes. The
13 non-synonymous mutant genes were RNF207, FAM107B, PALD1, CDH23, SPON2, SLC37A1, PRDM10, and FPR1 (Table II). 
Table I. SNP sites existing in more than 3 groups of carcinomatous elements in the exon area.

\begin{tabular}{|c|c|c|c|c|c|c|}
\hline Gene & Chr & Start & End & Ref & Mut & Mutation type \\
\hline KIF17 & 1 & 20704549 & 20704549 & $\mathrm{~T}$ & A & Non-synonymous \\
\hline $\mathrm{MROH} 2 \mathrm{~B}$ & 5 & 41008678 & 41008678 & A & $\mathrm{G}$ & Non-synonymous \\
\hline UBQLN3 & 11 & 5508690 & 5508690 & G & $\mathrm{C}$ & Non-synonymous \\
\hline HLA-DPB 1 & 6 & 33080761 & 33080761 & $\mathrm{~T}$ & $\mathrm{C}$ & Non-synonymous \\
\hline RP1L1 & 8 & 10616532 & 10616532 & $\mathrm{~T}$ & G & Non-synonymous \\
\hline SBSPON & 8 & 73092896 & 73092896 & A & G & Non-synonymous \\
\hline IQCE & 7 & 2604885 & 2604885 & $\mathrm{C}$ & $\mathrm{T}$ & Non-synonymous \\
\hline FMN1 & 15 & 33067373 & 33067373 & $\mathrm{C}$ & A & Non-synonymous \\
\hline ZNF592 & 15 & 84798628 & 84798628 & G & A & Non-synonymous \\
\hline ALPK2 & 18 & 59537018 & 59537018 & A & $\mathrm{C}$ & Non-synonymous \\
\hline FCGBP & 19 & 39902034 & 39902034 & G & $\mathrm{T}$ & Non-synonymous \\
\hline C19orf54 & 19 & 40749595 & 40749595 & $\mathrm{C}$ & G & Non-synonymous \\
\hline ZFHX3 & 16 & 72957816 & 72957816 & A & G & Non-synonymous \\
\hline
\end{tabular}

SNV, single-nucleotide polymorphism.

Table II. SNP sites existing in more than 3 groups of sarcomatoid elements in the exon region.

\begin{tabular}{|c|c|c|c|c|c|c|}
\hline Gene & Chr & Start & End & Ref & Mut & Mutation type \\
\hline RNF207 & 1 & 6218354 & 6218354 & A & G & Non-synonymous \\
\hline FAM107B & 10 & 14774449 & 14774449 & G & A & Non-synonymous \\
\hline PALD1 & 10 & 70530022 & 70530022 & $\mathrm{C}$ & $\mathrm{T}$ & Non-synonymous \\
\hline $\mathrm{CDH} 23$ & 10 & 71784329 & 71784329 & G & A & Non-synonymous \\
\hline SPON2 & 4 & 1171342 & 1171342 & G & $\mathrm{T}$ & Non-synonymous \\
\hline SLC37A1 & 21 & 42565845 & 42565845 & G & A & Non-synonymous \\
\hline PRDM10 & 11 & 129925055 & 129925055 & $\mathrm{~T}$ & $\mathrm{C}$ & Non-synonymous \\
\hline FPR1 & 19 & 51746419 & 51746419 & A & $\mathrm{C}$ & Non-synonymous \\
\hline
\end{tabular}

SNV, single-nucleotide polymorphism.

Target gene selection. Notably, among the 21 common mutant genes in more than three groups of sarcomatoid elements in the exon area, there was a high frequent point mutation in exon 40 of CDH23 gene (c. G5411A) occurring concurrently in the three groups of sarcomatoid elements and two groups of carcinomatous elements. This point mutation is an SNP site of CDH23 gene in exon 40 namely, rs3802711 in the NCBI database, and the identified amino acid substitution (p.Arg1804Gln) is in the highly conserved calcium-binding sites of the extracellular cadherin 17 (EC17) domain. PolyPhen-2 analysis predicated that the mutation (p.Arg1804Gln) may be involved in damaging the structure and function of $\mathrm{CDH} 23$ with a score of 1.000 (Fig. 3A). The three-dimensional (3D) structure of models predicted by SWISS-MODEL revealed a typical folding pattern with several $\beta$-strands. The p.Arg1804Gln was observed to be in the highly conserved EC calcium-binding sites in the cadherin repeat domain. The 3D structure of the mutation region of CDH23 (p.Gln1804; Fig. 3B) was different from that of the wild-type protein (p. Arg1804; Fig. 3C), which could disturb the protein function and interaction with other proteins.
Clinicopathological characteristics of 40 patients with CCRCCS and 50 patients with CCRCC. The clinicopathological characteristics of 40 patients with CCRCCS and 50 patients with CCRCC are presented in Table III. Compared with CCRCC, CCRCCS were larger in diameter $(7.7 \mathrm{~cm}$ vs. $2.6 \mathrm{~cm} ; \mathrm{P}<0.001)$, and more frequently associated with metastasis (18 vs. $2 ; \mathrm{P}<0.001)$ and local invasion (stage T3/T4, 21 vs. 3; $\mathrm{P}<0.001)$. The follow-up data were available in 34 patients with CCRCCS and 42 patients with CCRCC. Cancer-specific survival of CCRCCS was poorer than that of CCRCC, and 17 patients with CCRCCS succumbed 3-24 months after the surgery, while only three patients with CCRCC succumbed 17-22 months after the surgery.

Frequencies of CDH23 genotype in CCRCCS and CCRCC. Sanger sequencing results revealed that among the 40 specimens with CCRCC, 22 specimens exhibited A genotype (rs3802711) at the 5411th base of the CDH23 gene, and only 18 presented G genotype (wild-type, WT). Among the 22 mutant specimens, three were observed to be heterozygous mutations and the others were observed to be homozygous 

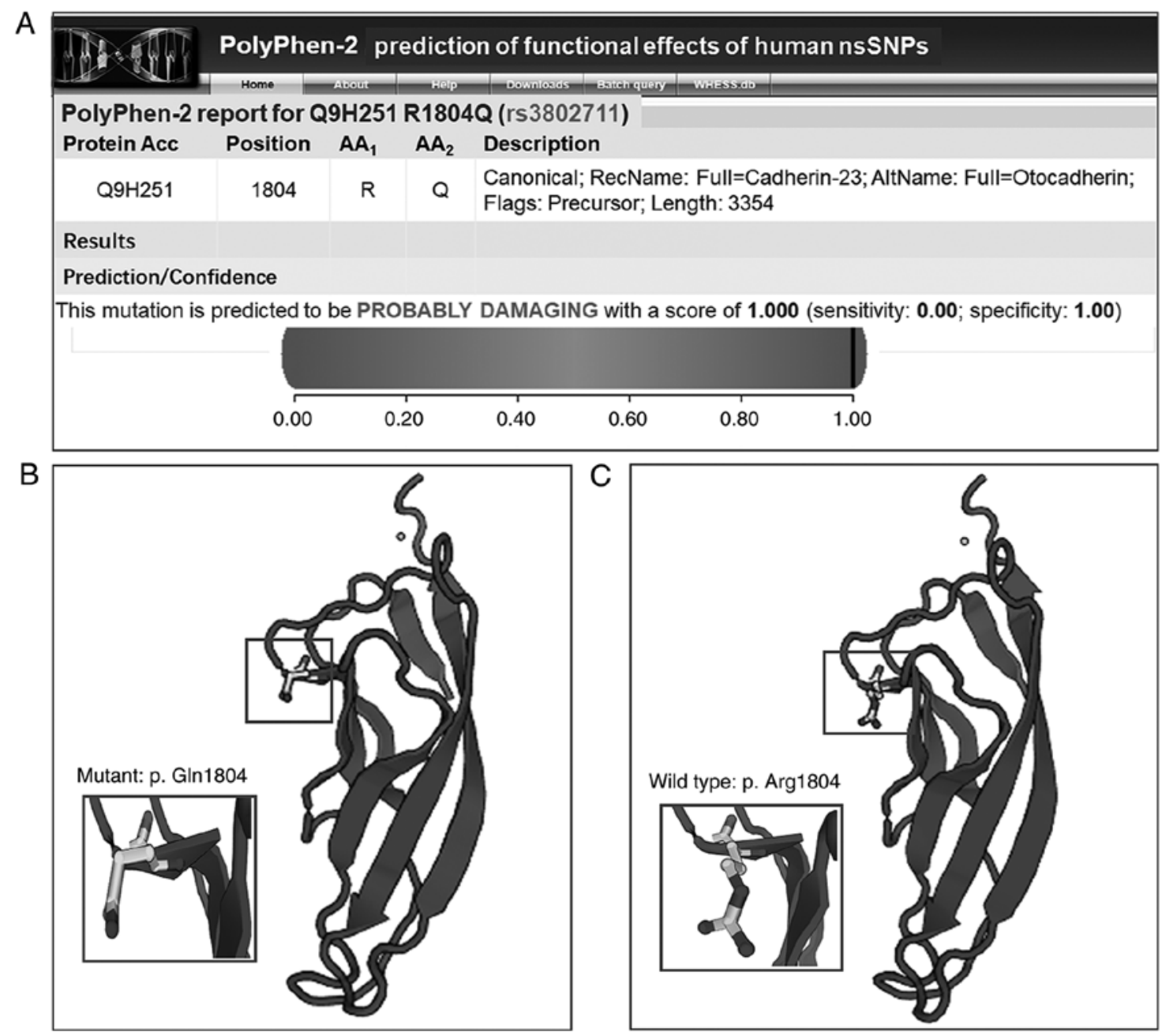

Figure 3. (A) PolyPhen-2 analysis predicted that the mutation was probably damaging to the structure and function of the CDH23 protein with a score of 1.000 . SWISS-MODEL revealed p.Arg1804Gln located in the highly conserved EC calcium-binding site, and the mutation altered the three-dimensional structure (B, mutant; C, wild type). $\mathrm{CDH} 23$, cadherin 23; EC, extracellular.

mutations (Fig. 4A-D). Carcinomatous and sarcomatoid elements in the same CCRCCS showed similar genotype at the 5411th base of the CDH23 gene. Whereas, among the 50 specimens with CCRCCS, 40 uniformly displayed G genotype (WT) rather than A genotype (rs3802711). Among the 10 mutant specimens, only one was a heterozygous mutation (Fig. 4E and F). There was a significant difference in the genotypic frequency ( $\mathrm{rs} 3802711)$ of the $\mathrm{CDH} 23$ gene between CCRCCS and CCRCC (55 vs. $20 \%, \chi^{2}=11.88$, $\mathrm{P}=0.001$; Table IV). The genotypic frequency (rs3802711) of the $\mathrm{CDH} 23$ gene between CCRCCS and high-grade CCRCC (Grade III-IV) revealed a significant difference (55 vs. $18.2 \%$, $\mathrm{P}=0.042$; Table IV). Furthermore, the genotypic frequency (rs3802711) of the CDH23 gene in CCRCCS is higher than that in low-grade CCRCC (Grade I-II) (55 vs. $20.5 \%, \mathrm{P}=0.002$; Table IV). The normal renal tissues of the 90 specimens were all wild-types. There was no significant association between $\mathrm{CDH} 23$ mutation and a series of clinicopathological features of CCRCCS including the age, sex, tumor diameter, metastasis, TNM stage, and survival of patients (Table V).

Kaplan-Meier analysis and Cox multivariate analysis for the factors affecting the overall survival of patients with
$R C C$. Kaplan-Meier analysis revealed that the clinicopathological features, including, distant metastasis (Fig. 5A and B), TNM stage (Fig. 5A and B), CDH23 SNP type (rs3802711) (Fig. 5A and B) and tumor diameter (Fig. 5B) were associated with the overall survival of a total of 90 RCCs. The Cox multivariate analysis indicated that the tumor diameter and $\mathrm{CDH} 23$ SNP type were the independent prognostic factors affecting the overall survival of the 90 RCCs (Fig. 5B).

Expression of the CDH23 gene in CCRCCS and CCRCC. In RT-qPCR analysis, CDH23 gene expression was observed to be lower in 21 cases with CCRCCS (Fig. S3) than that in 34 cases with CCRCC ( $\mathrm{P}<0.001$; Fig. S4; Table VI).

Expression of the CDH23 protein in CCRCCS and CCRCC. Through immunohistochemistry, the positive expression rates of the $\mathrm{CDH} 23$ protein in CCRCCS and CCRCC were observed to be $42.5 \%$ (17/40) and $76 \%$ (38/50), respectively ( $\mathrm{P}=0.001)$, exhibiting a lower expression rate in CCRCCS compared with CCRCC (Fig. 6; Table VII). CDH23 protein expression in CCRCCS was not associated with clinicopathological characteristics, such as the age, sex, tumor diameter, metastasis, TNM stage, and survival of patients (Table SI). 
Table III. Comparison of the clinicopathological features between CCRCCS and CCRCC

\begin{tabular}{|c|c|c|c|c|}
\hline \multirow[b]{2}{*}{ Characteristics } & \multicolumn{2}{|c|}{ Groups } & \multirow[b]{2}{*}{$\chi^{2} / \mathrm{t}$-test } & \multirow[b]{2}{*}{ P-value } \\
\hline & $\begin{array}{c}\text { CCRCCS } \\
(\mathrm{n}=40)\end{array}$ & $\begin{array}{c}\text { CCRCC } \\
(\mathrm{n}=50)\end{array}$ & & \\
\hline \multicolumn{5}{|l|}{ Sex } \\
\hline Male & 30 & 32 & 1.255 & 0.263 \\
\hline Female & 10 & 18 & & \\
\hline \multicolumn{5}{|l|}{ Age } \\
\hline Median & 63 & 59 & 1.607 & 0.112 \\
\hline \multicolumn{5}{|l|}{ Diameter $(\mathrm{cm})$} \\
\hline Median & 7.7 & 2.64 & 12.692 & $<0.001^{\mathrm{a}}$ \\
\hline \multicolumn{5}{|l|}{ Metastasis } \\
\hline No & 22 & 48 & 21.613 & $<0.001^{\mathrm{a}}$ \\
\hline Yes & 18 & 2 & & \\
\hline \multicolumn{5}{|l|}{ TNM stage } \\
\hline I-II & 19 & 47 & 24.571 & $<0.001^{\mathrm{a}}$ \\
\hline III-IV & 21 & 3 & & \\
\hline
\end{tabular}

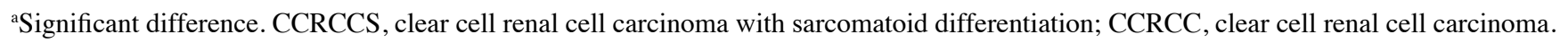
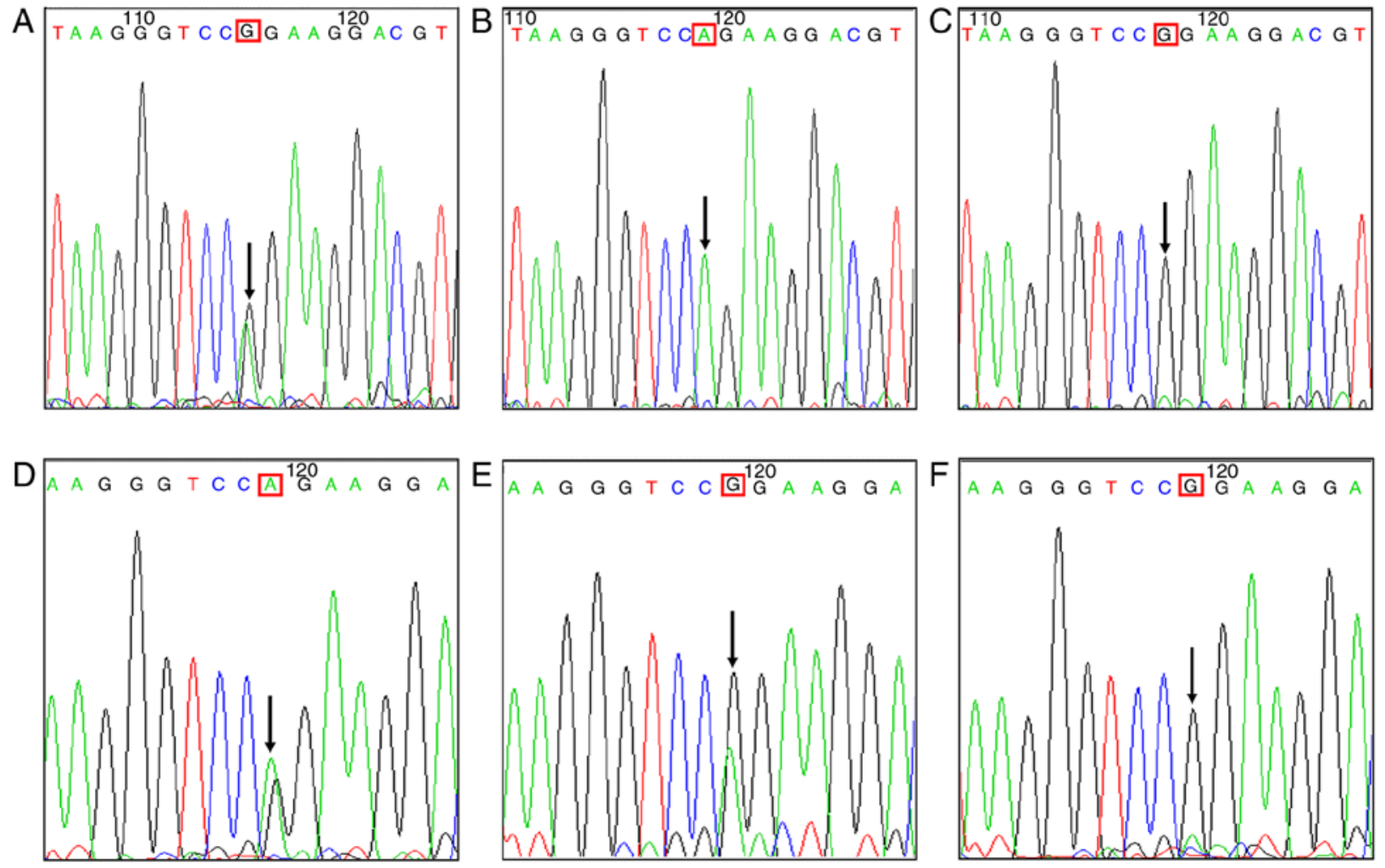

Figure 4. Sanger sequencing revealed the genotype of the CDH23 gene: (A) heterozygous mutation (A/G), (B) homozygous mutation (A/A), and (C) wild-type $(\mathrm{G} / \mathrm{G})$ in sarcomatoid elements of CCRCCS; (D) heterozygous mutation (A/G) in carcinomatous elements of CCRCCS; (E) heterozygous mutation (A/G) and (F) wild-type (G/G) in CCRCC. CDH23, cadherin 23; CCRCCS, clear cell renal cell carcinoma with sarcomatoid differentiation; CCRCC, clear cell renal cell carcinoma.

Correlation between the genotype of the CDH23 gene and expression of the CDH23 protein in a total of 90 studied cases. The genotype (rs3802711) of the CDH23 gene was significantly positively correlated with the expression of the $\mathrm{CDH} 23$ protein in 90 studied cases $(\mathrm{P}<0.001)$. The $\mathrm{CDH} 23$ protein was negatively or weakly expressed in most CCRCCS 
Table IV. Comparison of the frequencies of rs3802711 (A) and wild-type (G) of CDH23 in CCRCCS and CCRCC.

\begin{tabular}{lccccr}
\hline & & \multicolumn{2}{c}{ SNP of CDH23 } & & \\
\cline { 3 - 5 } Groups & $\mathrm{N}$ & rs3802711 (A) & Wild-type (G) & $\chi^{2}$ & P-value \\
\hline CCRCCS & 40 & 22 & 18 & 11.88 & $0.001^{\mathrm{a}}$ \\
CCRCC & 50 & 10 & 40 & & $0.042^{\mathrm{a}}$ \\
CCRCCS & 40 & 22 & 18 & & $0.002^{\mathrm{a}}$ \\
CCRCC (Grade III-IV) & 11 & 2 & 9 & 9.971 & \\
CCRCCS & 40 & 8 & 31 & & \\
CCRCC (Grade I-II) & 39 & 22 & 18 & & \\
\hline
\end{tabular}

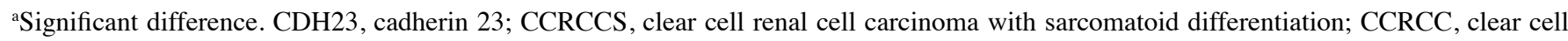
renal cell carcinoma; SNP, single-nucleotide variant.

Table V. The association between the genotype frequency of the CDH23 gene with the clinicopathological features of CCRCCS.

SNP of CDH23

\begin{tabular}{|c|c|c|c|c|c|}
\hline \multirow[b]{2}{*}{ Groups } & \multirow[b]{2}{*}{$\mathrm{N}$} & & \multirow[b]{2}{*}{$\chi^{2}$} & \multirow[b]{2}{*}{ P-value } \\
\hline & & rs3802711 (A) & Wild-type (G) & & \\
\hline \multicolumn{6}{|l|}{ Sex } \\
\hline Male & 30 & 16 & 14 & 0.135 & 0.714 \\
\hline Female & 10 & 6 & 4 & & \\
\hline \multicolumn{6}{|l|}{ Age } \\
\hline$\leq 63$ & 20 & 9 & 11 & 1.616 & 0.204 \\
\hline$>63$ & 20 & 13 & 7 & & \\
\hline \multicolumn{6}{|l|}{ Diameter } \\
\hline$\leq 8.0$ & 24 & 11 & 13 & 2.037 & 0.154 \\
\hline$>8.0$ & 16 & 11 & 5 & & \\
\hline \multicolumn{6}{|l|}{ Metastasis } \\
\hline No & 22 & 10 & 12 & 1.800 & 0.180 \\
\hline Yes & 18 & 12 & 6 & & \\
\hline \multicolumn{6}{|c|}{ TNM stage } \\
\hline I- II & 19 & 8 & 11 & 2.431 & 0.119 \\
\hline III-IV & 21 & 14 & 7 & & \\
\hline Survival & - & - & - & - & $>0.05$ \\
\hline
\end{tabular}

$\mathrm{CDH} 23$, cadherin 23; CCRCCS, clear cell renal cell carcinoma with sarcomatoid differentiation.

specimens with $\mathrm{CDH} 23$ mutation indicating that the mutation impaired the expression of the $\mathrm{CDH} 23$ protein (Table VIII).

\section{Discussion}

Given the characteristics of aggressive growth, early metastasis, extremely poor prognosis, and short survival time of CCRCCS, the pathogenesis of sarcomatoid elements is a key point and has always been an obstacle in renal tumor research. With the advent of next generation sequencing (NGS), few researchers have applied this technology to the research of CCRCCS. In a previous study, it was revealed that CCRCCS was more likely to lose $9 \mathrm{q}, 15 \mathrm{q}, 18 \mathrm{p} / \mathrm{q}$ and $22 \mathrm{q}$, and gain 1q and 8q than CCRCC, papillary renal cell carcinoma and chromophobe renal cell carcinoma. Furthermore, CCRCCS was revealed to have a higher CNV burden through SNP microarray analysis (24). Malouf et al (25) revealed that TP53, VHL, CDKN2A, and NF2 were most susceptible to mutation through next generation sequencing of 26 tumors with CCRCCS. CCRCCS and CCRCC had some different tumor-driving genes, and CCRCCS exhibited higher CNV burdens. Sircar et al (26) carried out cDNA microarray and RNA-sequencing to reveal that CCRCCS was molecularly distinct from non-sarcomatoid CCRCC, with its genetic programming mostly shared by the epithelioid and sarcomatoid elements. 
A
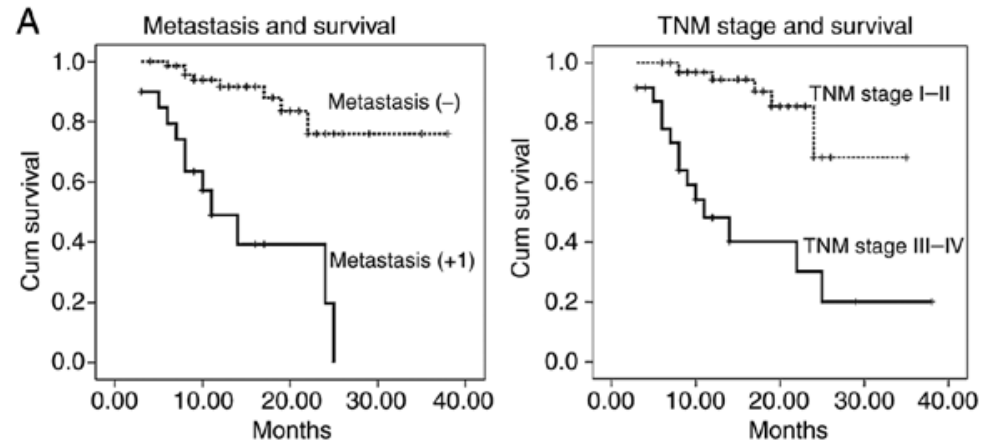

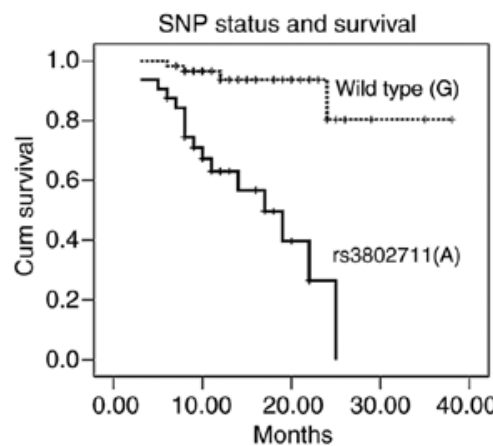

B

\begin{tabular}{|l|c|c|c|c|}
\hline \multirow{2}{*}{ Group } & \multicolumn{2}{|c|}{ Univariate analysis } & \multicolumn{2}{c|}{ Multivariate analysis } \\
\cline { 2 - 5 } & $\mathrm{HR}(95 \% \mathrm{Cl})$ & $\mathrm{P}$-value & $\mathrm{HR}(95 \% \mathrm{Cl})$ & P-value \\
\hline Sex & $0.200(0.046-0.879)$ & 0.033 & - & - \\
\hline Age & $1.008(0.963-1.055)$ & 0.742 & - & - \\
\hline Diameter $(\mathrm{cm})$ & $1.437(1.247-1.655)$ & $<0.001$ & $1.314(1.131-1.526)$ & $<0.001$ \\
\hline Metastasis & $0.125(0.049-0.316)$ & $<0.001$ & - & - \\
\hline TNM stage & $8.355(3.172-22.006)$ & $<0.001$ & $0.190(0.060-0.604)$ & 0.005 \\
\hline SNP status & $0.099(0.033-0.300)$ & $<0.001$ & & - \\
\hline
\end{tabular}

Figure 5. (A) Kaplan-Meier revealed that distant metastasis, TNM stage, and the CDH23 genotype were associated with the overall survival of the 90 cases. (B) Cox multivariate analysis indicated that the tumor diameter and the CDH23 genotype were independent prognostic factors affecting the overall survival of the cohort. CDH23, cadherin 23.
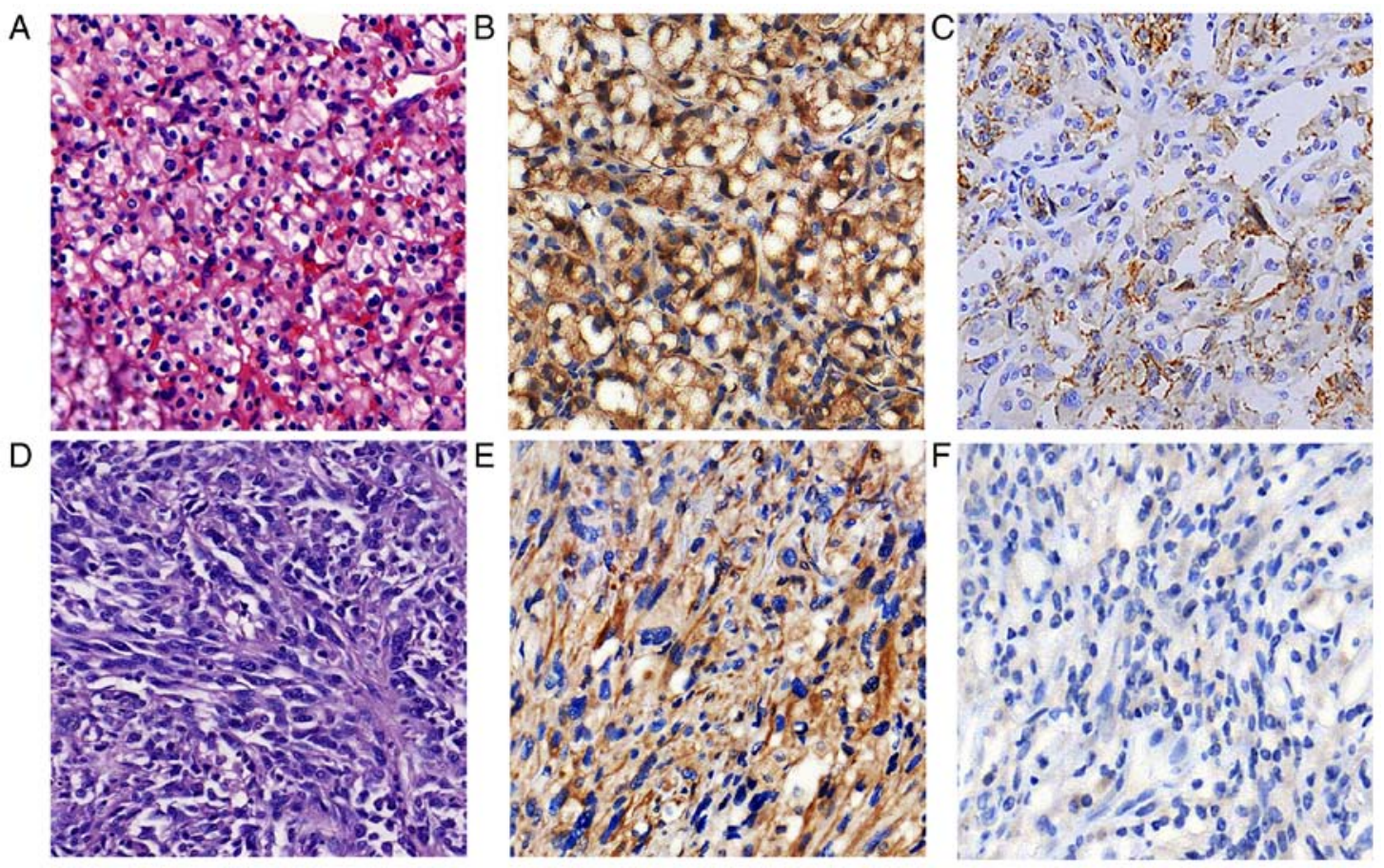

Figure 6. The morphology of (A) CCRCC (H\&E, x400), (B) strong expression and (C) weak expression of CDH23 in CCRCC (immunohistochemistry, $\mathrm{x} 400$ ). (D) The morphology of sarcomatoid elements of CCRCCS (H\&E, x400), (E) strong expression and (F) negative expression of CDH23 in sarcomatoid elements of CCRCCS (immunohistochemistry, x400). CCRCC, clear cell renal cell carcinoma; H\&E, hematoxylin and eosin; CDH23, cadherin 23; CCRCCS, clear cell renal cell carcinoma with sarcomatoid differentiation.

However, to date, the molecular mechanisms of sarcomatoid transformation had not been well elucidated. In the present study, the whole exome sequencing results revealed that most SSNVs were shared between carcinomatous and sarcomatoid elements providing reliable evidence that these elements originated from a common ancestor. Bi et al (6) revealed that the two elements had the same mutations with an average of $42 \%$ shared SSNVs through exome sequencing. The data in the present study and the previous literature $(6,26)$ have provided strong evidence of a carcinomatous origin of the two elements. However, the burden of element-specific SSNVs in known cancer drivers was higher in sarcomatoid elements than 
Table VI. CDH23 gene expression in CCRCCS and CCRCC.

$$
\begin{gathered}
\mathrm{CDH} 23 \text { gene } \\
\text { expression }
\end{gathered}
$$

\begin{tabular}{lccccc} 
Group & $\mathrm{N}$ & Negative & Positive & $\chi^{2}$ & P-value \\
\hline CCRCCS & 21 & 16 & 5 & 17.429 & $<0.001^{\text {a }}$ \\
CCRCC & 34 & 6 & 28 & & \\
\hline
\end{tabular}

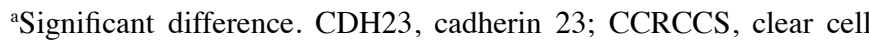
renal cell carcinoma with sarcomatoid differentiation; CCRCC, clear cell renal cell carcinoma.

Table VII. CDH23 protein expression in CCRCCS and

\begin{tabular}{|c|c|c|c|c|c|}
\hline \multirow[b]{2}{*}{ Group } & \multirow[b]{2}{*}{$\mathrm{N}$} & \multicolumn{2}{|c|}{$\begin{array}{l}\mathrm{CDH} 23 \text { protein } \\
\text { expression }\end{array}$} & \multirow[b]{2}{*}{$\chi^{2}$} & \multirow[b]{2}{*}{ P-value } \\
\hline & & Negative & Positive & & \\
\hline CCRCCS & 40 & 23 & 17 & 10.494 & $0.001^{\mathrm{a}}$ \\
\hline CCRCC & 12 & 38 & & & \\
\hline
\end{tabular}
CCRCC.

aSignificant difference. CDH23, cadherin 23; CCRCCS, clear cell renal cell carcinoma with sarcomatoid differentiation; CCRCC, clear cell renal cell carcinoma.

Table VIII. The association between the genotype of the $\mathrm{CDH} 23$ gene and the $\mathrm{CDH} 23$ protein expression in CCRCCS and CCRCC.

\begin{tabular}{lcccccc}
\hline & \multicolumn{5}{c}{$\begin{array}{c}\text { CDH23 protein } \\
\text { expression }\end{array}$} \\
\cline { 3 - 4 } Genotype & N & Negative & Positive & r & P-value \\
\hline rs3802711 (A) & 25 & 7 & 5 & 0.598 & $<0.001^{\text {a }}$ \\
Wild-type (G) & 10 & 48 & & & \\
\hline
\end{tabular}

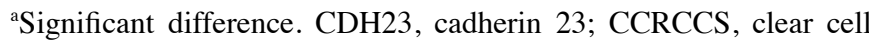
renal cell carcinoma with sarcomatoid differentiation; CCRCC, clear cell renal cell carcinoma.

in carcinomatous elements suggesting that the sarcomatoid element has arisen in a process of de-differentiation from a preexisting carcinomatous element during the progression of tumors, which was consistent with previous studies $(6,26)$.

To investigate the element-specific mutant genes, 319 common mutant genes occurring in more than three groups of carcinomatous elements, and 360 common mutant genes emerging in more than three groups of sarcomatoid elements were obtained. Most mutant genes in carcinomatous elements were involved in the same functions as those in sarcomatoid elements. However, some mutant genes played specific roles in carcinomatous elements, including Ras signaling pathway, cell adhesion molecules, cytokine-cytokine receptor interaction, and central carbon metabolism in cancer. Furthermore, in sarcomatoid elements, some distinct genes were specifically involved in regulation of actin cytoskeleton, focal adhesion, FOXO signaling pathway, MAPK signaling pathway, PI3K/Akt signaling pathway, and vascular smooth muscle contraction, which may be involved in the transformation of sarcomatoid elements in CCRCCS. Among them, there were 25 common mutant genes in more than three groups of carcinomatous elements in the exon region, including 13 non-synonymous mutant genes KIF17, MROH2B, UBQLN3, HLA-DPB1, RP1L1, SBSPON, IQCE, FMN1, ZNF592, ALPK2, FGCBP, C19orf54 and ZFHX3. Another 21 common mutant genes in more than three groups of sarcomatoid elements in the exon region contained eight non-synonymous mutant genes RNF207, FAM107B, PALD1, CDH23, SPON2, SLC37A1, PRDM10, and FPR1. These genes may act as candidate genes, further revealing the molecular mechanisms of sarcomatoid transformation in CCRCCS.

Notably, simultaneous occurrence of non-synonymous mutation of CDH23 c.G5411A (p.Arg1804 Gln), an SNP locus of $\mathrm{CDH} 23$ namely, rs3802711, in two groups of carcinomatous elements and three groups of sarcomatoid elements drew our attention. It has been reported that the $\mathrm{CDH} 23$ is a member of cadherin family that plays crucial roles in epithelial and mesenchymal transformation of tumors. Furthermore, Sanger sequencing in extended samples with CCRCCS and CCRCC revealed that the frequency of $\mathrm{CDH} 23$ mutation (rs3802711) was significantly higher in CCRCCS compared to CCRCC. Moreover, the frequency of $\mathrm{CDH} 23$ mutation (rs3802711) was markedly higher in CCRCCS than that in high-grade CCRCC (Fuhrman grade III-IV). It was also revealed that the sarcomatoid and carcinomatous elements in the same tumor shared similar CDH23 (rs3802711) mutation, which provided further evidence of a common origin of the two elements in CCRCCS.

CDH23 (NM_022124) is located on chromosome 10q21-q22, encoding a 3354aa atypical cadherin with an elongated extracellular region containing 27 EC domains, a single transmembrane domain, and a cytoplasmic domain that is mostly expressed in the cilia of neuroretina, cochlea, and vestibular hair cells, but also in the brain, heart, lung, kidney, nose, eye, and ear cells (27). The repeat EC domains are highly conserved among human, mice and rats, which responsibly mediate the functions of cadherin members. Thus far, most research concerning $\mathrm{CDH} 23$ had been focused on its association with hearing loss. Various mutations in $\mathrm{CDH} 23$ have resulted either in the loss of tip links or hair cell death causing sensorineural deafness (DFNB12), USH1D, age-related HL or noise-induced HL $(12,13)$. Certain deafness mutations in CDH23, including p.Pro240Leu, p.Glu1595Lys, p.Asn342Ser, and p.Glu1595Lys may have affected highly conserved calcium binding motifs in the EC domain or in the linker region between the EC domain, both of which are essential for calcium binding or dimerization of $\mathrm{CDH} 23$, and then impaired cell-to-cell adhesion through calcium-dependent interactions $(28,29)$. Zhang et al (30) identified a new non-synonymous heterozygous mutation c.G 4136T (p.Arg1379Leu) in CDH23 in pituitary adenoma through whole exome sequencing, which caused an amino acid substitution in the calcium-binding 
motif of the EC domains of $\mathrm{CDH} 23$ and was predicted to impair cell-cell adhesion.

In the present study, p.Arg1804GIn was revealed as a new variant in $\mathrm{CDH} 23$ that was not shared with either hearing loss or pituitary adenoma, and none of the patients in the present study were linked to any symptoms of deafness or pituitary adenoma. PolyPhen-2 analysis predicted the mutation (p.Arg1804Gln) that may be involved in damaging the structure and function of $\mathrm{CDH} 23$. Furthermore, the normal 3D structure of $\mathrm{CDH} 23$ was impaired in the mutant protein (p.Arg1804Gln) predicted by SWISS-MODEL, which could disturb the protein function and its interaction with other proteins. Furthermore, the CDH23 gene and protein were negatively or weakly expressed in most CCRCCS specimens with $\mathrm{CDH} 23$ mutation indicating that the mutation of $\mathrm{CDH} 23$ impaired the expression of $\mathrm{CDH} 23$ and then disturbed its normal function. Cox multivariate analysis indicated that the CDH23 SNP type was an independent prognostic factor affecting the overall survival of the total study cohort, including CCRCC and CCRCCS, despite being independently associated with the prognosis of patients with CCRCCS. The possible interpretation was that a variety of factors may be involved in the sarcomatoid transformation and prognosis of CCRCCS, of which the CDH23 (rs3802711) genotype may be a high genetic risk factor of sarcomatoid transformation and a predictive factor for the poor prognosis of RCCs.

The role of $\mathrm{CDH} 23$ in cancer has not been fully elucidated. Cadherins are well known to play crucial roles in EMT, through which the epithelial cells are reprogrammed to become mesenchymal cells, lose adhesion, and are prone to metastasis. The altered cadherin expression is a known marker for EMT, mainly including cadherin 1 (E-Cadherin), cadherin 2 , cadherin 4 , cadherin 13 , cadherin 3 , and cadherin 11 (31). $\mathrm{CDH} 23$ is a unique non-classic member of the cadherin family that lacks the $\beta$-catenin binding motif anchoring to the actin cytoskeleton to mediate intercellular adhesion. The CDH23 interacting partners, such as USH1C and MAGI-1 are known to interact with the actin cytoskeleton to anchor the proteins that may play important roles in the $\mathrm{CDH} 23$ anchorage mechanism and cellular adhesion (32). However, studies have revealed its possible role in complex diseases, such as cancer and Alzheimer's disease $(33,34)$. CDH23 has been recently reported to mediate predominant heterotypic cell adhesion between the epithelial cells and fibroblasts, thus playing an important role in breast cancer cell metastasis through the TGF- $\beta$ pathway. The TGF- $\beta$ signaling pathway could enhance cell invasion, migration, and an immunosuppressive effect (7). CDH23 may be involved in EMT and tumor metastasis similarly to the other cadherins. CDH23 mutations have always been studied with respect to hearing loss, but exploring the somatic mutations in $\mathrm{CDH} 23$ and protein expression levels in various carcinomas, especially in carcinoma with sarcomatoid differentiation will be helpful in further understanding its role in EMT and tumor metastasis (35). However, the mechanisms through which CDH23 is involved in EMT and tumor metastasis have not been reported to date. As the future direction of our research, we plan to perform RNA sequencing in cell lines to screen the upstream and downstream factors related to $\mathrm{CDH} 23$ after the overexpression or knockdown of $\mathrm{CDH} 23$, which may be helpful to explain the molecular mechanisms of $\mathrm{CDH} 23$ in the CCRCCS process.
The present study has identified, for the first time, the CDH23 SNP (rs3802711) as a high genetic risk factor for CCRCCS. CDH23 mutation (rs3802711) was associated with the decreased expression of the $\mathrm{CDH} 23$ protein, resulting in the absence of cadherin function of $\mathrm{CDH} 23$, which indicated that the $\mathrm{CDH} 23$ mutation may be involved in the sarcomatoid transformation in CCRCCS. Furthermore, the present results provided a new prognostic evaluation factor and potential target therapeutic site for CCRCCS. New insight was gained into the molecular mechanisms of sarcomatoid transformation in CCRCCS and a new prognosis evaluation factor for CCRCCS was revealed. Furthermore, a novel and specific SNP of CDH23 was identified in CCRCCS and a new candidate cadherin involved in EMT was revealed. These results have implications for the therapy of patients with this type of tumor which has a poor prognosis. However, a greater number of tumors with CCRCCS are required for study and further functional studies of the $\mathrm{CDH} 23$ gene are required to gain insights into the detailed pathogenic mechanisms involved in CCRCCS.

\section{Acknowledgements}

Not applicable.

\section{Funding}

The present study was supported by the Natural Science Foundation of Shandong Province (ZR2017MH009), and the National Natural Science Foundation of China (81201654).

\section{Availability of data and materials}

The datasets analyzed during the present study are publicly available from the following online databases: PolyPhen-2, http://genetics.bwh.harvard.edu/pph2/; SWISS-MODEL, https://swissmodel.expasy. org/interactive; https://www.ncbi. nlm.nih.gov/pubmed/.

\section{Authors' contributions}

WY designed the study, analyzed the data and wrote the manuscript. XW performed Sanger sequencing and analyzed the data. YW analyzed and interpreted the data of the study. WZ analyzed the imaging features, clinical data and IHC results. YJ and YL reviewed the pathologic diagnosis and contributed to the conception and design of the study. HS performed the IHC experiment and mRNA extraction. YL also revised the manuscript critically for important intellectual content. All authors read and approved the final version of the manuscript and agree to be accountable for all aspects of the work in ensuring that questions related to the accuracy or integrity of any part of the work are appropriately investigated and resolved.

\section{Ethics approval and consent to participate}

This study was performed in accordance with standard guidelines and was approved by the Ethics Committee of the Affiliated Hospital of Qingdao University. All patients provided informed consent. 


\section{Patient consent for publication}

Not applicable.

\section{Competing interests}

The authors declare that they have no competing interests.

\section{References}

1. Nguyen DP, Vilaseca A, Vertosick EA, Corradi RB, Touijer KA, Benfante NE, Sjoberg DD and Russo P: Histologic subtype impacts cancer-specific survival in patients with sarcomatoid-variant renal cell carcinoma treated surgically. World J Urol 34: 539-544, 2016.

2. Farrow GM, Harrison EG Jr, Utz DC and ReMine WH: Sarcomas and sarcomatoid and mixed malignant tumors of the kidney in adults. Cancer 22: 556-563, 1968.

3. Moch H, Cubilla AL, Humphrey PA, Reuter VE and Ulbright TM: The 2016 WHO Classification of tumours of the urinary system and male genital organs-part a: Renal, penile, and testicular tumours. Eur Urol 70: 93-105, 2016.

4. Trudeau V, Larcher A, Sun M, Boehm K, Dell'Oglio P, Sosa J, Tian Z, Fossati N, Briganti A, Shariat SF and Karakiewicz P: Comparison of oncologic outcomes between sarcomatoid and clear cell renal cell carcinoma. World J Urol 34: 1429-1436, 2016.

5. Morra L, Rechsteiner M, Casagrande S, Duc Luu V, Santimaria R, Diener PA, Sulser T, Kristiansen G, Schraml P, Moch H and Soltermann A: Relevance of periostin splice variants in renal cell carcinoma. Am J Pathol 179: 1513-1521, 2011.

6. Bi M, Zhao S, Said JW, Merino MJ, Adeniran AJ, Xie Z, Nawaf CB, Choi J, Belldegrun AS, Pantuck AJ, et al: Genomic characterization of sarcomatoid transformation in clear cell renal cell carcinoma. Proc Natl Acad Sci USA 113: 2170-2175, 2016.

7. Shuch B, Bratslavsky G, Linehan WM and Srinivasan R: Sarcomatoid renal cell carcinoma: A comprehensive review of the biology and current treatment strategies. Oncologist 17: 46-54, 2012.

8. Jones TD, Eble JN, Wang M, Maclennan GT, Jain S and Cheng L: Clonal divergence and genetic heterogeneity in clear cell renal cell carcinomas with sarcomatoid transformation. Cancer 104 1195-1203, 2005.

9. Shuch B, Said J, LaRochelle JC, Zhou Y, Li G, Klatte T, Pouliot F, Kabbinavar FF, Belldegrun AS and Pantuck AJ: Histologic evaluation of metastases in renal cell carcinoma with sarcomatoid transformation and its implications for systemic therapy. Cancer 116: 616-624, 2010.

10. Conant JL, Peng Z, Evans MF, Naud S and Cooper K: Sarcomatoid renal cell carcinoma is an example of epithelial-mesenchymal transition. J Clin Pathol 64: 1088-1092, 2011.

11. Siemens J, Lillo C, Dumont RA, Reynolds A, Williams DS, Gillespie PG and Müller U: Cadherin 23 is a component of the tip link in hair-cell stereocilia. Nature 428: 950-955, 2004.

12. Mizutari K, Mutai H, Namba K, Miyanaga Y, Nakano A, Arimoto Y, Masuda S, Morimoto N, Sakamoto H, Kaga K and Matsunaga T: High prevalence of $\mathrm{CDH} 23$ mutations in patients with congenital high-frequency sporadic or recessively inherited hearing loss. Orphanet J Rare Dis 10: 60, 2015.

13. Schultz JM, Bhatti R, Madeo AC, Turriff A, Muskett JA, Zalewski CK, King KA, Ahmed ZM, Riazuddin S, Ahmad N, et al: Allelic hierarchy of $\mathrm{CDH} 23$ mutations causing non-syndromic deafness DFNB12 or Usher syndrome USH1D in compound heterozygotes. J Med Genet 48: 767-775, 2011.

14. Taniuchi K, Nakagawa H, Hosokawa M, Nakamura T, Eguchi H, Ohigashi H, Ishikawa O, Katagiri $\mathrm{T}$ and Nakamura $\mathrm{Y}$ : Overexpressed $\mathrm{P}$-cadherin/CDH3 promotes motility of pancreatic cancer cells by interacting with p120ctn and activating rho-family GTPases. Cancer Res 65: 3092-3099, 2005.

15. Li H and Durbin R: Fast and accurate short read alignment with Burrows-Wheeler transform. Bioinformatics 25: 1754-1760, 2009.

16. $\mathrm{Li} \mathrm{H}$ and Durbin R: Fast and accurate long-read alignment with Burrows-Wheeler transform. Bioinformatics 26: 589-595, 2010.
17. Cibulskis K, Lawrence MS, Carter SL, Sivachenko A, Jaffe D, Sougnez C, Gabriel S, Meyerson M, Lander ES and Getz G: Sensitive detection of somatic point mutations in impure and heterogeneous cancer samples. Nat Biotechnol 31: 213-219, 2013.

18. McKenna A, Hanna M, Banks E, Sivachenko A, Cibulskis K, Kernytsky A, Garimella K, Altshuler D, Gabriel S, Daly M and DePristo MA: The Genome Analysis Toolkit: A MapReduce framework for analyzing next-generation DNA sequencing data. Genome Res 20: 1297-1303, 2010.

19. Yang $\mathrm{H}$ and Wang $\mathrm{K}$ : Genomic variant annotation and prioritization with ANNOVAR and wANNOVAR. Nat Protoc 10: 1556-1566, 2015.

20. Chang $X$ and Wang K: wANNOVAR: Annotating genetic variants for personal genomes via the web. J Med Genet 49: 433-436, 2012.

21. Adzhubei I, Jordan DM and Sunyaev SR: Predicting functional effect of human missense mutations using polyphen-2. Curr Protoc Hum Genet 7: Unit7.20, 2013.

22. Waterhouse A, Bertoni M, Bienert S, Studer G, Tauriello G, Gumienny R, Heer FT, de Beer TAP, Rempfer C, Bordoli L, et al: SWISS-MODEL: Homology modelling of protein structures and complexes. Nucleic Acids Res 46: (W1):W296-W303, 2018.

23. Livak KJ and Schmittgen TD: Analysis of relative gene expression data using real-time quantitative PCR and the 2 (Delta Delta $\mathrm{C}(\mathrm{T}))$ method. Methods 25: 402-408, 2001.

24. Ito T, Pei J, Dulaimi E, Menges C, Abbosh PH, Smaldone MC, Chen DY, Greenberg RE, Kutikov A, Viterbo R, et al: Genomic copy number alterations in renal cell carcinoma with sarcomatoid features. J Urol 195: 852-858, 2016.

25. Malouf GG, Ali SM, Wang K, Balasubramanian S, Ross JS, Miller VA, Stephens PJ, Khayat D, Pal SK, Su X, et al: Genomic characterization of renal cell carcinoma with sarcomatoid dedifferentiation pinpoints recurrent genomic alterations. Eur Urol 70: 348-357, 2016.

26. Sircar K, Yoo SY, Majewski T, Wani K, Patel LR, Voicu H, Torres-Garcia W, Verhaak RG, Tannir N, Karam JA, et al: Biphasic elements of sarcomatoid clear cell renal cell carcinomas are molecularly similar to each other, but distinct from, non-sarcomatoid renal carcinomas. J Biphasic Pathol Clin Res 1: 212-224, 2015.

27. Diez-Roux G, Banfi S, Sultan M, Geffers L, Anand S, Rozado D, Magen A, Canidio E, Pagani M, Peluso I, et al: A high-resolution anatomical atlas of the transcriptome in the mouse embryo. PLoS Biol 9: e1000582, 2011.

28. Woo HM, Park HJ, Park MH, Kim BY, Shin JW, Yoo WG and Koo SK: Identification of $\mathrm{CDH} 23$ mutations in Korean families with hearing loss by whole-exome sequencing. BMC Med Genet 15: 46, 2014.

29. Kowalski TJ, Pawelczyk M, Rajkowska E, Dudarewicz A and Sliwinska-Kowalska M: Genetic variants of $\mathrm{CDH} 23$ associated with noise-induced hearing loss. Otol Neurotol 35: 358-365, 2014.

30. Zhang Q, Peng C, Song J, Zhang Y, Chen J, Song Z, Shou X, Ma Z, Peng H, Jian X, et al: Germline mutations in CDH23, encoding cadherin-related 23 , are associated with both familial and sporadic pituitary adenomas. Am J Hum Genet 100: 817-823, 2017.

31. Karlsson MC, Gonzalez SF, Welin J and Fuxe J: Epithelial-mesenchymal transition in cancer metastasis through the lymphatic system. Mol Oncol 11: 781-791, 2017.

32. Zaric J, Joseph JM, Tercier S, Sengstag T, Ponsonnet L, Delorenzi $M$ and Rüegg C: Identification of MAGI1 as a tumor-suppressor protein induced by cyclooxygenase-2 inhibitors in colorectal cancer cells. Oncogene 31: 48-59, 2012.

33. De Jager PL, Srivastava G, Lunnon K, Burgess J, Schalkwyk LC, Yu L, Eaton ML, Keenan BT, Ernst J, McCabe C, et al: Alzheimer's disease: Early alterationsin brain DNA methylation at ANK1, BIN1, RHBDF2 and other loci. Nat Neurosci 17: 1156-63, 2014.

34. Lunnon K, Smith R, Hannon E, De Jager PL, Srivastava G, Volta M, Troakes C, Al-Sarraj S, Burrage J, Macdonald R, et al: Methylomic profiling implicates cortical deregulation of ANK1 in Alzheimer's disease. Nat Neurosci 17: 1164-1170, 2014.

35. Vanniya SP, Srisailapathy CRS and Kunka Mohanram R: The tip link protein Cadherin-23: From hearing loss to cancer. Pharmacol Res 130: 25-35, 2018. 